\title{
Changes in the bacterial community structure and diversity during bamboo retting
}

\author{
Jiajia Fu', Henry Mueller ${ }^{2}$, Joao V de Castro Jr', Chonewen Yu', Artur Cavaco-Paulo ${ }^{3}$, Georg M. Guebitz ${ }^{2}$ and \\ Gibson S. Nyanhongo ${ }^{2}$ \\ ${ }^{1}$ Key Laboratory of Science and Technology of Eco-Textile, Ministry of Education (Donghua University), Shanghai, P. R. China \\ ${ }^{2}$ Institute of Environmental Biotechnology, Graz University of Technology, Graz, Austria \\ ${ }^{3}$ Department of Textile Engineering, University of Minho, Guimarães, Portugal
}

\begin{abstract}
Microbial retting is a critical step in obtaining fiber bundles from bamboo culm using indigenous microorganisms. A cultivation-independent technique for monitoring the changes in bacteria community during bamboo retting was applied in this work. This technique involves genetic profiling of PCR-amplified small-subunit rRNA and the single-strand conformation polymorphism (SSCP) gel analysis of the PCR-amplified 16S rDNA fragments. The study revealed that both the structure and the diversity of investigated communities varied with the incubation periods and sample locations. The bacteria bands from SCCP gel profiles related to Bacillus sp. decreased in intensity, and Phaeospirillum sp. and Azospirillum brasilense completely disappeared during the $4^{\text {th }}$ and $5^{\text {th }}$ month of incubation, while the bands related to the Sphingomonas japonica, Alphaproteobacterium Ellin335 and Microbacterium sp. increased. The bands closely related to Sphingomonads, Brevundimonas brasilense, Pseudoclavibacter sp., Agrococcus jenensis and Oxalophagus oxalicus remained dominant during the whole incubation period. This study showed that the use of PCR assay targeting 16 S rRNA and SCCP profiling provided valuable information on monitoring the bacteria dynamic changes occurring in the bacteria community during bamboo retting, which is crucial for controlling the quality of the retting process and improving the retting efficiency, and thus benefits for fiber recovery.
\end{abstract}

Keywords: Bacterial community $\cdot$ Bioretting $\cdot$ SSCP $\cdot$ PCR $\cdot$ Metagenomics

\section{Introduction}

Bamboo is one of the fastest growing and most abundant woody plants in tropical countries [1]. The rate of growth, up to $1 \mathrm{~m}$ per day, is very attractive for commercial applications. Therefore, bamboo is gaining increasing attention as an alternative crop with multiple utilizations. It is estimated that there are up to 1500 bamboo species having commercial potential [2]. Bamboo has recently at-

Correspondence: Dr. Chonewen Yu, Key Laboratory of Science and Technology of Eco-Textile, Ministry of Education (Donghua University), Shanghai, 201620, P. R. China

E-mail:yucw@dhu.edu.cn

Abbreviation: rDNA(RNA), ribosomal DNA(RNA)
Received 14 February 2011

Revised 23 March 2011

Accepted 15 April 2011 tracted a great deal of attention as a natural, green and eco-friendly new-type raw material for textile applications. The relatively long length of bamboo monofilaments $(1.5-3.2 \mathrm{~mm})$ [3] coupled with its antibacterial properties make it suitable for specialty textile materials such as sanitary napkins, bandages, surgical clothes and food-packing bags. Recently its potential value for textile yarn production has emerged [4-7].

Traditionally bamboo fiber is obtained through alkaline hydrolysis followed by multiple chemical bleaching steps; however, these processes are expensive and have negative effects on the environment. Therefore, alternative green technologies are

Colour online: See the article online to view Fig. 1 in colour. 
being investigated. Nevertheless, until now only a few studies have been dedicated to developing biological processes for bamboo fiber recovery [8-11], whereas extensive research has been conducted into enzymatic wood pulping [12-18]. Retting, based on enzymes (e.g., hemicellulases, cellulases, oxidoreductases, and pectinases) produced by an indigenous complex bacteria community (e.g., fermenting, homoacetogenic, syntrophic, and acetate-utilizing bacteria) to degrade cellular tissues and pectins, gums, etc., is gaining potential as a pretreatment step to obtain fibers from raw bast materials (e.g., jute, flax, hemp and kenaf). It facilitates separation of cellulose fiber bundles from the matrix [19-22] and has been shown to play an important role in determining the quality and yields of jute fiber [23]. Although retting is a crucial step for the production of fiber bundles, the available reports on the bacterial communities in the retting environments are scarce, with most literature coming from flax [24-27] and jute retting [20, 28]. The current knowledge of the microbial community is mainly based on culture-dependent studies [22, 25, 29-31]. However, cultivation-based approaches favor the growth of only certain community members, while a great part of the population is overlooked [32]. In fact, culture-based methods are reported to only account for $1 \%$ of the microorganisms present in an ecosystem and the remainder (99\%) of the microorganisms can not be characterized using the traditional culture techniques [33, 34]. Culture-independent $16 \mathrm{~S}$ rRNA gene-based studies of bacteria communities from various habitats have provided scientists with crucial information on the diversity and dynamics of these communities. For example, the potential applications of culture-independent studies (PCR assays targeting bacterium 16S rRNA genes) during the retting of jute provided insight into the changes in the bacteria communities during the retting process [23]. The use of such knowledge is expected to improve fiber bundle extraction in terms of quality and quantity. The present study was aimed at gaining an insight into the microbial communities and their changes during the retting of bamboo, making use of PCR assays targeting 16S rRNA genes and the single-strand conformation polymorphism (SSCP) gel analysis of the PCR-amplified 16S rRNA fragments. The SCCP profiling technique was chosen rather than denaturing gradient gel electrophoresis (DGGE) and temperature gradient gel electrophoresis (TGGE) because of its simplicity, the fact that it did not require a gradient, the absence of GC clamps and the ability to provide valuable information on changes in bacteria communities [32, $35,36]$. To the best of our knowledge, the present study is the first attempt to use culture-independent methods to monitor changes occurring in bacteria communities during the retting of bamboo. We are convinced this study will enable us to identify key microoganisms involved at every stage of the retting process. The universal bacteria community primers, as well as three other specific bacteria community primers (bacillus, actinomycete and alphaproteobacteria), which had been present in other retting systems [20, 23, 37, 38], were used. Furthermore, dominant bands were sequenced to provide information about the identity of the microorganism.

\section{Materials and methods}

\subsection{Sampling}

One-year old Moso bamboo (Phyllostachy) culms were harvested from bamboo gardens in Jiangxi Province, P. R. China. The culms from two different gardens were cut into small pieces and placed in two 2-L Erlenmeyer flasks with $1 \mathrm{~L}$ sterilized water as two independent retting systems. The flasks were incubated at $28^{\circ} \mathrm{C}$ with shaking at $150 \mathrm{rpm}$ in a chamber with controlled humidity at $60 \%$. The water lost due to potential evaporation was readjusted every 2 weeks. Samples (including bamboo and liquid) from the retting systems were withdrawn at different time intervals when observable changes of culm morphology were noted (i.e., after 1.5, 4 and 5 months).

\subsection{Bacterial community analysis}

\subsubsection{Extraction and purification of total genomic DNA}

The bacterial communities for the bamboo retting process were analyzed by culture-independent tools based on the PCR amplification of the 16S rRNA fragments and subsequent partial sequencing.

The DNA of the microbial community of the bamboo retting system was extracted by mechanical disruption and homogenization of $2 \mathrm{~g}$ samples including retted bamboo and retting liquid using a FastPrep Instrument (BIO 101 Systems: Qbiogene, Carlsbad, CA, USA) for $30 \mathrm{~s}$ at speed 5.0 and $400 \mathrm{mg}$ sample per time point. The total genomic DNA of bacterial-cell consortia was recovered using the FastDNA Spin Kit for Soil (Bio101, Carlsbad, CA) following the manufacturer's protocol and purified by the GENECLEAN Turbo kit (MP Biomedicals, Illkirch, France) containing the special binding buffer guanidine thiocyanate for the removal of humic acids. The quality and concentration of extracted DNA were estimated by electrophoresis on a 
$0.8 \%$ agarose gel running at $90 \mathrm{~V}$ for $30 \mathrm{~min}$ at room temperature and analyzed after ethidium bromide staining under ultra violet (UV) emission.

\subsubsection{Cultivation-independent analysis by SSCP gel} Fingerprinting of the Bamboo bacterial communities by SSCP was carried out as described by Schwieger and Tebbe [35] and using the Gene Ruler $1 \mathrm{~kb}$ DNA ladder, Fermentas, as standard. The reproducibility of the SSCP results was verified in two independent samplings at three time points $(1.5,4$ and 5 months) during the retting period. Bacterial 16S rDNA fragments (positions 515- 927 according to Escherichia coli 16S rRNA sequence numbering) were amplified by PCR with the primers Unibac-II-515f and Unibac-II-927r-P [39]. Alphaproteobacteria were selectively amplified by a nested PCR approach with primers ADF 681F/1492r (5'-AGT GTA GAG GTG AAA TT-3'/ 5'-TAC GGY TAC CTT GTT ACG ACT T-3') followed by a second PCR with the primers ADF 681F/ Unibac-II-927r-P (5'-CCC GCT AAT TYM TTT GAC TT-3') [40]. Bacillus amplicons were obtained with BLS342f/BACr833-P (5' - CAG CAG TAG GGA ATC TTC-3'/ 5'-CTA ACA CTT AGC ACT CAT-3') primers $[40,41]$. For specific patterns of actinomycetes, a nested PCR was applied with first PCR primer pair Eubac1/Eubac2 (5'- GAG TTT GAT CCT GGC TCA G-3'/5'-AGA AAG GAG GTG ATC CAG CC-3'), followed by a second PCR primer Actino243f / Actino513r-P (5'-GGA TGA GCC CGC GGC CTA-3' / 5'-CGG CCG CGG CTG GTG GCA CGT A-3') [42]. The PCR products were purified using a GeneClean Turbo Kit (Qbiogene, BIO101 ${ }^{\circledR}$ ), before exonuclease digestion and DNA singlestrand folding according to Lieber et al. [43]. The amplicons were separated using the TGGE Maxi system (Biometra, Göttingen, Germany) at $400 \mathrm{~V}$ and $26^{\circ} \mathrm{C}$. Eubacterial as well as bacillus-specific amplicons were separated in $8 \%$ acryl amide gels for $26 \mathrm{~h}$. DNA fragments of the Alphaproteobacteria- and actinomycete-specific PCR were separated in 9\% acryl amide gels for $16 \mathrm{~h}$. The gels were silver-stained according to the procedure of Bassam [44] for subsequent visualization.

\subsubsection{Analysis of SCCP profiles}

Evaluation of SSCP gel profiles of the bacterial communities in the bamboo-retting liquid was carried out using the GelCompar program (version 4.1; Applied Maths, Kortrijk, Belgium). Digitized gel images were obtained by scanning the silver-stained SSCP gels (Epson perfection 4990 Photo, Japan) for the community-fingerprint comparison. Individual SSCP patterns were normalized and the background was subtracted as recommended by the manufacturer. The band-based Dice similarity coefficient was applied for similarity matrix calculation [45]. The profiles generated were processed by UPGMA (Unweighted Pair Group Method with arithmetic Average) analysis and a dendrogram was deduced from the matrix of similarities.

\subsubsection{Calculation of diversity indices}

A diversity index based on the Shannon-Wiener diversity index $\left(\mathrm{H}^{\prime}\right)$ was adopted to characterize the differences in the genetic diversity of the various bacterial communities, and calculated as [46]:

$$
H^{\prime}=-\sum_{i=1}^{S}\left[\left(n_{i} / N\right) \ln \left(n_{i} / N\right)\right]
$$

where, $\mathrm{n}_{\mathrm{i}}$ is the relative abundance of a single taxon (intensity of a single SSCP band); $\mathrm{N}$ is the total abundance of all taxa (accumulated band intensity); $S$ is the total number of abundant species (total number of bands).

The diversity of the SSCP bands was calculated using the same GelCompar program mentioned above. The different peaks of a densitometric curve of each SSCP lane were analyzed.

\subsubsection{Sequence analysis}

Dominant bands corresponding to the different bacterial communities were excised from SSCP gels and the DNA recovered by elution according to Schwieger and Tebbe [35]. The gel-extracted DNA was re-amplified and sequenced. Bacteria were then identified by comparing the obtained sequences with sequences available in the GenBank database, using the NCBI BLAST program at http://www.ncbi.nlm.nih.gov/BLAST [47].

\section{Results}

\subsection{Bamboo retting process}

Morphological studies showed that retting resulted in the separation of fiber bundles from bamboo culm, regardless of bamboo source. The general process of bamboo retting is summarized in Figs. 1A-C. At the initial stage (Fig. 1A), the bamboo culms were intact, while with prolonged incubation the culms started to be loosen innerly (Fig. 1B). Further incubation led to the untwisting of the fiber bundles at the node level and separation of the bundles from the culm since the materials surrounding the fiber bundles were degraded (Fig, 1C). Microscopic inspection (Fig. 2) confirmed that a single bamboo bundle in a hollow structure 
A

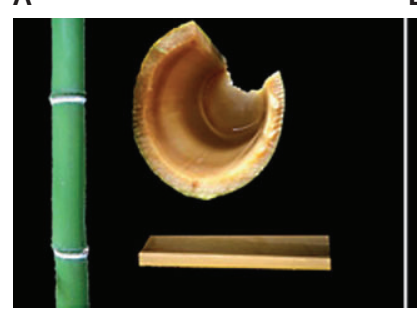

B

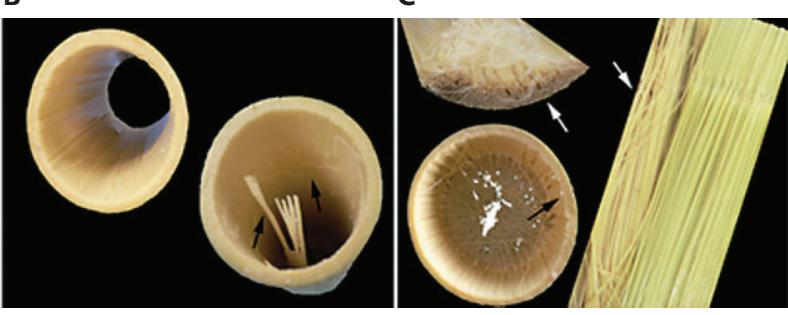

Figure 1. Morphological changes of bamboo culms during the retting process. (A) Initial stage where the bamboo is intact. (B) Bamboo fiber loosening and de-pilling. (C) Fibers separating from each other and falling into the lumen of the culm. contained many monofilaments with lumen and smooth surface.

\subsection{Bacterial community analysis}

\subsubsection{Universal bacteria community analysis}

SCCP profiles of universal bacteria community in both retting systems showed high reproducibility within replicates (Fig. 3), indicating that DNA sam-
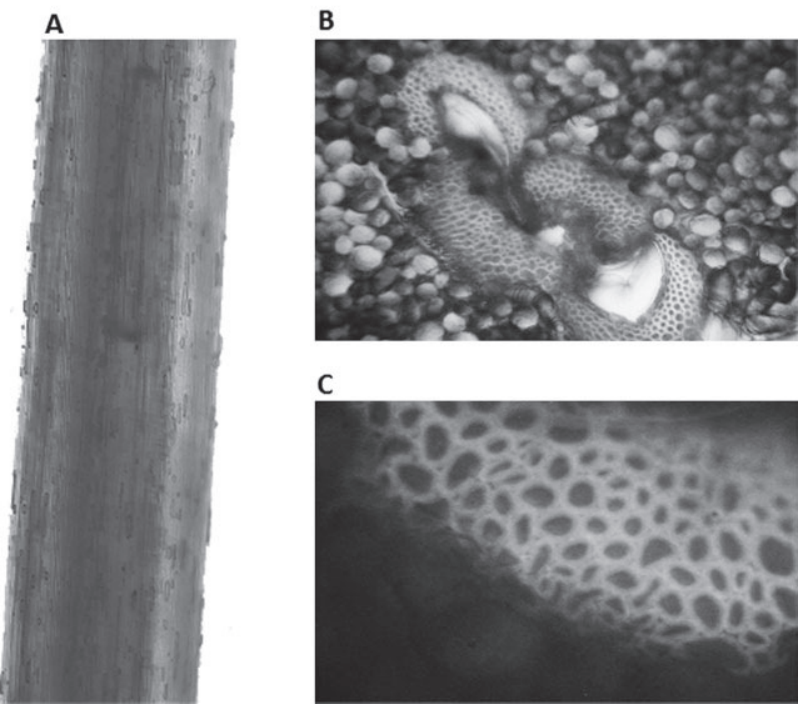

C

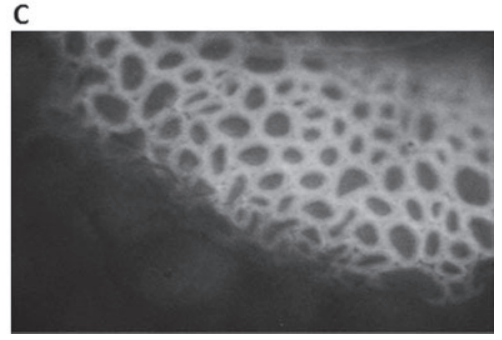

Figure 2. Morphology of a single bamboo fiber bundle (Nikon Eclipse 400 , in transmission mode). (A) Vertical section $(\times 40)$; (B) cross-section of a single bundle $(\times 100)$; (C) cross-section of bamboo bundle $(\times 400)$. ples were of high quality for further analysis. The partial sequence analyses and tentative close relations of specified SSCP bands are summarized in Table 1, showing a more predominant uncultured population in this category. The information of the uncultured bacteria population normally can not be obtained by the traditional culture-dependent method, i.e., the screening and isolation of the strains with various media. The sequences mainly correlated with uncultured Sphingobacterium sp. (bands 7 and 9) in retting system 1. In retting system 2, the sequences closely related to uncultured Paludibacter sp. (band 1), Candidatus Sulcia muelleri (band 2), uncultured Pedobacter sp. (band 3), Flavobacterium sp. (band 4), uncultured Porphyrobacter sp. (bands 5 and 6) and uncultured Planctomycete (band 8) showed dominant signals during the whole incubation period (Fig. 3). Interestingly, the intensity change of some specific bands differed with the samples from different regions. For example, bands 7 and 9, with strong density in retting system 1, decreased or disappeared along with the prolongation of the incubation time in retting system 2 . However, bands 1, 2 and 8, which completely disappeared during months 4 and 5 in retting system 1 remained strong in retting system 2. In general, visual inspection of SCCP banding patterns for universal bacteria communities (Fig. 3) revealed a gradual decrease in intensity and subsequent disappearance of some bands after 4 to 5 months of incubation in both retting systems

Table 1. Partial sequence analyses and tentative close relations of SSCP bands for universal bacteria community

\begin{tabular}{|c|c|c|c|}
\hline Band no. & Microhabitat most closely related sequence(s) & $S I^{a)}$ & GenBank accession no. \\
\hline 1 & Uncultured Paludibacter sp. & 91 & EU809705.1 \\
\hline 2 & Candidatus Sulcia muelleri & 91 & DQ066640.1 \\
\hline 3 & Uncultured Pedobacter sp. & 90 & GQ287498.1 \\
\hline 4 & Flavobacterium sp. SRS18 & 98 & AY621158 \\
\hline 5 & Uncultured Porphyrobacter sp. & 94 & EF662624.1 \\
\hline 6 & Uncultured Porphyrobacter sp. & 97 & EF662624.1 \\
\hline 7 & Uncultured Sphingobacterium sp. & 94 & FJ756565.1 \\
\hline 8 & Uncultured planctomycete & 85 & DQ870157.1 \\
\hline 9 & Uncultured Sphingobacterium sp. & 92 & FJ756565.1 \\
\hline
\end{tabular}

a) $\mathrm{SI}$, similarity index: for isolates identified by $16 \mathrm{~S}$ rDNA sequencing ranging from 0 to $100 \%$. 


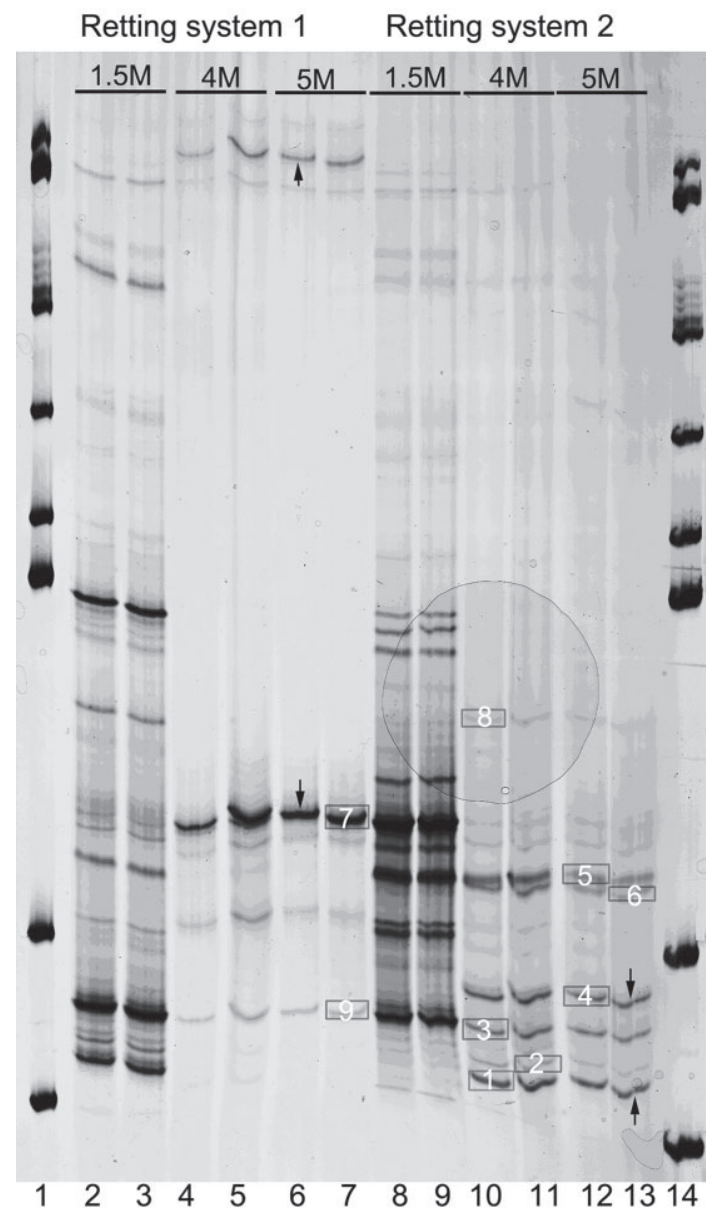

Figure 3. SCCP profiles showing the universal bacteria communities during bamboo retting in the retting system 1 and 2 at different sampling times [1.5 months (1.5M), 4 months $(4 \mathrm{M})$ and 5 months $(5 \mathrm{M})]$. The resolved bands in retting system 1 and 2 were very similar during the incubation period. Bands indicated by numbers (1-8) were purified and sequenced (for results, see Table 1); Gene Ruler 1-kb DNA ladder (Fermentas) was used as standard.

despite the fact that some bands showed a increase in density with long-term incubation (Fig. 3, arrows).
The highest diversity represented by the Shannon-Wiener index $\mathrm{H}^{\prime}$ was observed at the first sampling time $\left(\mathrm{H}^{\prime}=3.17 \pm 0.02\right.$ and $3.35 \pm 0.00$ for retting system 1 and 2 , respectively). In the following 3-4-month period, the complexity of the SSCP profiles decreased, revealing a reduction of diversity $\left(\mathrm{H}^{\prime}=2.00 \pm 0.01\right.$ and $2.78 \pm 0.01$ for retting system 1 and 2 after 4 months, respectively, and $\mathrm{H}^{\prime}=1.85 \pm 0.00$ and $2.56 \pm 0.02$ for retting system 1 and 2 after 5 months, respectively) and an enrichment of specialized bacteria. The changes were also reflected in the dendrograms (Fig. 4A), clearly showing a higher similarity between the bacterial communities after 4 and 5 months (about $87 \%$ for both retting systems) than between the profiles after 1.5 months and the later sampling points (44\% for retting system 1 and $64 \%$ for retting system 2 ).

\subsubsection{Alphaproteobacteria community analysis}

Group-specific primer systems were used to selectively amplify 16S rDNA fragments of Alphaproteobacteria. The dominant and individual bands with strong intensity and clear shape were excised from SSCP gels for DNA recovery. The partial sequence analyses and tentative close relations of the bands are listed in Table 2. Bands closely related to Alphaproteobacterium Ellin335 (band 3 in both retting systems and band 4 in retting system 2) and Sphingomonas japonica (band 7 in retting system 2) increased in intensity during months 4 and 5, while bands corresponding to Phaeospirillum sp. (band 6 in both retting systems) and Azospirillum brasilense (band 1 in retting system 1) disappeared after 4 months. Interestingly, the sequence related to Brevundimonas diminuta (band 2) remained dominant and showed a remarkable intensity during the whole incubation time in both retting systems. Band 5 (in retting system 1) and band 8 (in retting system 2) corresponding to Kaistia sp. and uncultured Sphingomonas sp., respectively, were relatively weak in density throughout the whole incubation time.

Table 2. Partial sequence analyses and tentative close relations of SSCP bands for the alphaproteobacteria community

\begin{tabular}{cccc}
\hline Band no. & Microhabitat most closely related sequence(s) & S|a) & GenBank accession no. \\
\hline 1 & Azospirillum brasilense & 96 & $\mathrm{AB} 480703.1$ \\
2 & Brevundimonas diminuta & 95 & $\mathrm{FJ} 843099.1$ \\
3 & Alphaproteobacterium Ellin335 & $\mathrm{AF} 498717.1$ \\
4 & Alphaproteobacterium Ellin335 & 97 & $\mathrm{AF} 498717.1$ \\
5 & Kaistia sp. & 91 & $\mathrm{FJ71} 79344.1$ \\
6 & Phaeospirillum sp. & 93 & $\mathrm{FJ529718.1}$ \\
7 & Sphingomonas japonica & 94 & $\mathrm{AB} 428568.1$ \\
8 & Uncultured Sphingomonas sp. & 91 & $\mathrm{AM} 936457.1$ \\
\hline
\end{tabular}

a) SI, similarity index: for isolates identified by $16 \mathrm{~S}$ rDNA sequencing ranging from 0 to $100 \%$. 


\section{A}
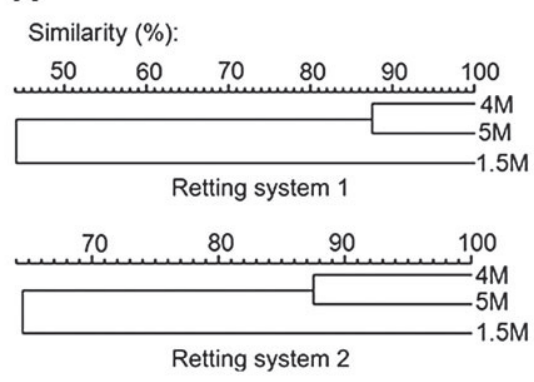

C

Similarity (\%):
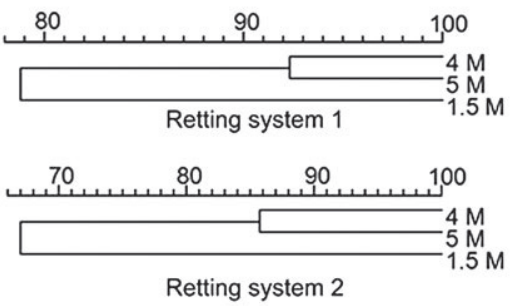

B

Similarity (\%):
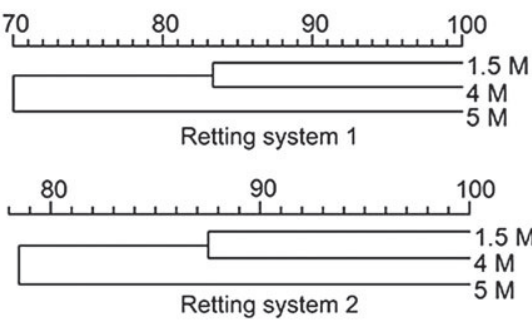

D

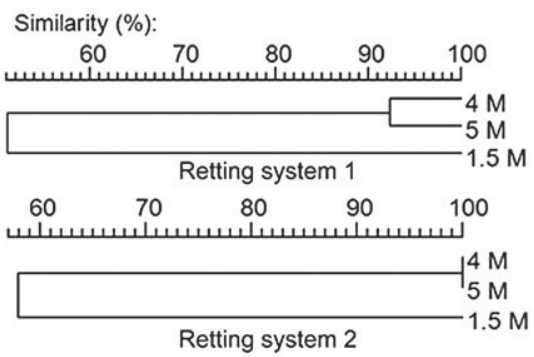

Figure 4. Constructed dendrogram based on amplified fragments using different community analysis primers. (A) Universal bacteria community; (B) alphaproteobacteria community; (C) actinomycete community; (D) bacillus community.
The diversity of alphaproteobacteria community in both retting systems decreased with increasing incubation time. The highest diversity represented by the Shannon-Wiener index $\mathrm{H}^{\prime}$ was observed at the first sampling time $\left(\mathrm{H}^{\prime}=1.74 \pm 0.02\right.$ and $2.00 \pm 0.06$ for retting system 1 and 2 , respectively). In the following 3-4 months there was a reduction in diversity $\left(\mathrm{H}^{\prime}=1.70 \pm 0.01\right.$ and $1.81 \pm 0.04$ for retting system 1 and 2, respectively, after 4 months and $\mathrm{H}^{\prime}=1.06 \pm 0.04$ and $1.56 \pm 0.06$ for retting system 1 and 2 , respectively, after 5 months).

The dendrogram in Fig. $4 \mathrm{~A}$ clearly reveals that in comparison with the universal bacteria community analysis, the similarity of alphaproteobacteria community was higher in both retting systems (above $80 \%$ ) before 4 months. The similarity remained high at around 70\% in retting system 1 and $78 \%$ in retting system 2 after 5 months of retting.

\subsubsection{Actinomycete community analysis}

Generally, SSCP patterns of actinomycete populations revealed only minor changes up to month 4 of the retting process. Thus, the Shannon-Wiener's diversity index remained stable at $1.75 \pm 0.17$ and $1.91 \pm 0.14$ for retting system 1 and 2 , respectively. The dominant and representative bands were excised from SSCP gel. The recovered DNA was sequenced and results are presented in Table 3. Bands with the same partial 16S rRNA gene as Pseudoclavibacter sp. (band 3) and Agrococcus jenensis (band 5) were amazingly dominant during the whole incubation period in both retting systems. Bands closely related to Rhodococcus erythropolis (band 1) and Demequina aestuarii (band 4) decreased in density when assayed after 4 months of incubation, while bands mainly concerned with $M i$ crobacterium sp. (band 2) increased intensity after 4 months of incubation in both retting systems. Further, in comparison with the universal bacteria and alphaproteobacteria community analysis, BLAST sequence analysis of the actinomycete community showed a higher maximum identity index $>98 \%$ and identified sequences of predominant bands were related to cultivable microbes.

Table 3. Partial sequence analyses and tentative close relations of SSCP bands for the actinomycete community

\begin{tabular}{cccc}
\hline Band no. & Microhabitat most closely related sequence(s) & SI ${ }^{\text {a) }}$ & GenBank accession no. \\
\hline 1 & Rhodococcus erythropolis & 99 & AP008957.1 \\
2 & Microbacterium sp. & 99 & 98 \\
3 & Pseudoclavibacter sp. & 99 & EU654436.1 \\
4 & Demequina aestuarii & DQ010160.1 & 99 \\
5 & Agrococcus jenensis & FJ482044.1 & \\
\hline
\end{tabular}

a) SI, similarity index: for isolates identified by $16 \mathrm{~S}$ rDNA sequencing ranging from 0 to $100 \%$. 
Table 4. Partial sequence analyses and tentative close relations of SSCP bands for the bacillus community

\begin{tabular}{cccc}
\hline Band no. & Microhabitat most closely related sequence(s) & SI & GenBank accession no. \\
\hline 1 & Oxalophagus oxalicus & 99 & Y14581.1 \\
2 & Oxalophagus oxalicus & 94 & 98 \\
3 & Bacillus sp. NSJ-14 & 87 & FJ941090.1 \\
4 & Bacillus sp. th9 & 88 & EU814517.1 \\
5 & Bacillus sp. BD-94 & 99 & AF169523.1 \\
6 & Oxalophagus oxalicus & Y14581.1 \\
\hline
\end{tabular}

a) SI, similarity index: for isolates identified by $16 \mathrm{~S}$ rDNA sequencing ranging from 0 to $100 \%$.

The dendrogram in Fig. 4C show that community similarity was higher between 4 and 5 month (above $85 \%$ in both retting systems), indicating a great change occurring between 1.5 and 4 months, and then became tempered in the following month. This change trend was in accordance with universal bacteria community.

\subsubsection{Bacillus community analysis}

SCCP gel profiles of bacillus community for both retting systems were identical and showed a similar pattern and band intensity. The visible and dominant bands were excised and DNA was recovered. The sequence results are listed in Table 4 . Bands with the same partial 16S rRNA gene as Oxalophagus oxalicus (bands 1, 2 and 6) were dominant during the whole incubation period in both retting systems. Bands related to Bacillus sp. NSJ-14 (band 3) and Bacillus sp. th9 (band 4) showed slightly decreased intensity after 1.5 months of incubation in both retting systems, while the band related to Bacillus sp. BD-94 (band 5) dramatically decreased in intensity and finally disappeared after 4 months of incubation.

The Shannon-Wiener index $\mathrm{H}^{\prime}$ of both retting systems decreased with increasing incubation time. For retting system 1, $\mathrm{H}^{\prime}$ declined from $2.7 \pm 0.04$ at 1.5 months to $1.70 \pm 0.02$ at 4 and 5 months, while in retting system $2, \mathrm{H}^{\prime}$ reduced from $2.37 \pm 0.01$ at 1.5 months to $1.85 \pm 0.02$ at 4 and 5 months. Therefore, the huge diversity change also occurred between 1.5 and 4 months and then maintained relatively constant from 4 to 5 months. The dendrogram (Fig. 4D) reveals that the community at 4 and 5 months gained a higher similarity (above $92 \%)$ for two retting systems, in line with the diversity analysis.

\section{Discussion}

Culture-independent molecular biology based techniques were used to investigate changes of the microbial community during bio-retting of bam- boo. Due to the fact that cultivatable microbes comprise a minority (approximately 1\%) of total community diversity $[33,48]$ previous studies on microbial retting based on cultivation may have overlooked a major part of the microbial community. As evidenced by the Shannon-Wiener $\mathrm{H}^{\prime}$ index, the diversity of the total bacteria in the microbial retting environment investigated in this study tended to decrease with increasing incubation time. This was also confirmed by the analysis of SSCP profiles obtained with universal bacteria, alphaproteobacteria and bacillus community primers showing a general decrease in number of bands and/or decrease in intensity when compared to the bands profiles obtained at 1.5 months, although fluctuating changes were observed for the actinomecyte community. Strong correlations between changes in microbial succession patterns (taxonomic and functional diversity) during plant cell wall degradation and the sequential utilization of nutrients have been reported [49]. Similarly, in this study, the bands intensity, for example, closely related to Bacillus sp., Rhodococcus erythropolis, Sphingobacterium sp. and Demequina aestuarii decreased, while, in particular, Phaeospirillum sp. and Azospirillum brasilense disappeared completely between 4 and 5 months of incubation. A few bands related to Alphaproteobacterium Ellin335, Sphingomonas japonica and Microbacterium sp. increased intensity from 1.5 to 4 months. For other lignocellulosic materials, the early phases of retting are known to be dominated by organisms that can attack the easily accessible polysaccharides, like pectins, monosaccharides and gums [49]. Similarly, in this study, the initial phase of bamboo retting proved to be the most dynamic part of the process, and it is assumed that each bacterial population at this stage plays a special role in trying to change the chemical environment to favor for its own survival [50]. However, as more complex substrates (hemicellulose interlinked with lignin) remained, only those microorganisms with a complex enzymatic system were able to survive. The disappearance of certain microorganisms during the retting process at 4 and 
5 months, confirmed by SCCP profiles, indicates sequential metabolism of simple substrates followed by degradation of complex materials. Indeed, organisms identified during the latter phase are well known for the production of extracellular enzymes (including oxidases) that degrade complex materials. For example, Sphingomonas sp. are able degrade complex substrates like lignin, and Sphingomonas paucimobilis SYK-6 has been shown to be able to degrade a wide variety of dimeric lignin compounds, including $\beta$-aryl ether, biphenyl, and diarylpropane [51, 52]. Many Bacillus sp. are also widely reported to produce enzymes of industrial application in paper industry [53-60] and bast fiber degumming [61, 62]. Consequently, pretreatment with the combined Sphingomonas paucimobilis and Bacillus strains improved the hydrolysis of office paper from municipal wastes [63], justifying the observed presence of both organisms during the incubation period. Interestingly, although members of the Actinomycetes genus have been reported to develop more slowly than most other microorganisms, and are comparatively ineffective competitors under high-nutrient conditions [64], in this study bacteria with the same partial 16S rRNA gene as Pseudoclavibacter were quite dominant during the whole incubation period and bacteria related to Microbacterium greatly increased in band density at 4 months. This is not surprising since a $\mathrm{Mi}$ crobacterium sp. was recently isolated for its ability to degrade xylan [65]. We also tried to analyze the pseudomonas community (data not shown), and two bands closely related to Pseudomonas sp. T8 and Pseudomonas sp. T7 (100\% by max ident) were dominant during the whole incubation period. Similarly, in previous jute-retting studies, Pseudomonas sp. was also shown to be dominant and was attributed to their ability to secrete a set of enzymes that enable the degradation of plant cell wall components [20]. Pseudomonas sp. are widely distributed in the environment and are known to participate in $\mathrm{N}_{2}$ fixation, denitrification and degradation of pollutants [66-68]. Although little is known about $\mathrm{Ox}$ alophagus oxalicus, the survival and dominance of bands closely related to it during the whole incubation period requires special attention since its high frequency may suggest a significant role during the retting process. As clearly indicated by the SSCP profile of universal bacteria community, the band patterns differed between the two retting systems. This was mainly attributed to the fact that the samples originated from two different gardens, which may have had different environmental conditions (e.g., temperature, humidity, air, or soil quality) for microorganisms, and finally led to the difference in bacterial community. The fungal com- munity studies in the retting systems based on 18S rRNA fungus-specific primers were not successful. This may be due to the culture conditions (liquid system), since fungi prefer moisture and the observation are in line with previous studies with flax- [21, 24] and jute- [20] retting systems.

This study showed that the cultivation-independent technique for genetic profiling of PCRamplified small-subunit rRNA and the SSCP gel analysis of the PCR-amplified 16S rDNA fragments can be used for monitoring the changes in bacterial communities occurring during the retting of bamboo. The SCCP profile analysis revealed that the bacterial community changed during the retting of bamboo, leading to a general decrease in diversity. Most of the DNA recovered from the dominant bands were sequenced and classified as uncultivable microorganisms confirmed by previous reports. The obtained information can be exploited in various ways, including identifying the microorganisms and isolating key microorganisms involved in during the retting process. Such pure cultures could then be bioagumented to enhance the retting process. On-going studies are aimed at investigating the natural retting system of bamboo obtained from different geographical regions. This study forms a novel basis on which such future studies can be built.

This work was made possible by the support from the earmarked fund for Modern Agro-industry Technology Research System (nycytx-19-E23), the European Union Biorenew Project [Sixth Framework Programme (FP6-2004-NMP-NI-4)] and China Scholarship Council. The authors would like to thank Florian Schmid, Herbert Pobeheim, Stefan Weiß, Michael Fürnkranz, Christoph Schmidt and Endry Nugroho Prasetyo for a number of insightful comments and suggestions.

The authors have declared no conflict of interest.

\section{References}

[1] Scurlock, J. M. O., Dayton, D. C., Hames, B., Bamboo: an overlooked biomass resource? Biomass Bioenerg. 2000, 19, 229244.

[2] Ohrnberger, D. (Ed.), The bamboos of the world: annotated nomenclature and literature of the species and the higher and lower taxa, Elsevier, Amsterdam 1999.

[3] Bassam, N. El. (Ed.), Energy plant species: their use and impact on environment and development, James and James, London 1998. 
[4] Cheng, L. D., Xu, X. L., Lao, J. H., An analysis on the morphological structure and property of bamboo fiber. China Text. Leader 2003, 101-103.

[5] Fan, J., Bamboo fiber - A new type textile fiber material. Tianjin Text. Sci. Technol. 2005, 35-38.

[6] Wang, X. L., Xu, J. H., Zhou, G. Y., Recent development and perspective of bamboo fiber, J. Anhui Agri. Sci. 2006, 34, 1578-1579.

[7] Su, Y. F., Yang, S. T., Bamboo fiber and product development. Shanxi Text. Chem. Fiber 2005, 2-6.

[8] Li, H., Zhou, G. Y., Zhou, D. M., Extraction of bamboo fiber through screening of fungus. J. Central. South Forestry Univ. 2006, 15, 68-71.

[9] Fu, J. J., Yang, X. X., Yu, C. W., Enzymatic treatment of crude bamboo fibers, in: Proceedings of the 2007 International Conference on Advanced Fibers and Polymer Materials, Chemical Industry Press, Shanghai 2007, pp. 724-726.

[10] Fu, J. J., Yang, X. X., Yu C. W., Preliminary research on bamboo degumming with xylanase. Biocatal. Biotransform. 2008, $25,450-454$.

[11] Deng, S. Z., Guo, Y. J., Fu, J. J., Yu, C. W., Study on bio-enzymatic degumming of bamboo fiber. Plant Fiber Sci. China 2009, 31, 41-44.

[12] Bourbonnais, R., Paice, M. G., Demethylation and delignification of kraft pulp by Trametes versicolor laccase in the presence of 2,2'-azinobis-(3-ethylbenzthiazoline-6-sulfonate). Appl. Microbiol. Biot. 1992, 36, 823-827.

[13] Leduc, C., Daneault C., Delaunois, P., Jaspers, C. et al., Enzyme pretreatment of kraft pulp to reduce consumption of bleach chemicals. Appita J. 1995, 48, 435-439.

[14] Bourbonnais, R., Paice, M. G., Enzymatic delignification of kraft pulp using laccase and a mediator. Tappi J. 1996, 79, 199-204.

[15] Bourbonnais, R., Paice, M. G., Freiermuth, B., Bodie, E. et al., Reactivities of various mediators and laccases with kraft pulp and lignin model compounds. Appl. Environ. Microb. 1997, 63, 4627-4632.

[16] Bajpai, P., Application of enzymes in the pulp and paper industry. Biotechnol. Prog. 1999, 15, 147-157.

[17] Clarke, J. H., Rixon, J. E., Halstead, J. R., Fransen, M. P. et al., A comparison of enzyme-aided bleaching of softwood paper pulp using combinations of xylanase, mannanase and alpha-galactosidase. Appl. Microbiol. Biotechnol. 2000, 53, 661-667.

[18] Kenealy, W. R., Jeffries, T. W., Enzyme processes for pulp and paper: A review of recent developments. Wood Deter. Pres. 2003, 845, 210-239.

[19] Di Candilo, M., Bonatti, P. M., Guidetti, C., Focher, B. et al., Effects of selected pectinolytic bacterial strains on water-retting of hemp and fibre properties. J. Appl. Microbiol. 2009, 108, 194-203.

[20] Munshi, T. K., Chattoo, B. B., Bacterial population structure of the jute-retting environment. Microb. Ecol. 2008, 56, 270282.

[21] Rosemberg, J. A., Bacteria responsible for the retting of Brazilian flax. Appl. Environ. Microbiol. 1965, 13, 991-992.

[22] Yu, H. Q., Yu, C. W., Study on microbe retting of kenaf fiber. Enzyme Microb. Technol. 2007, 40, 1806-1809.

[23] Ahmed, Z., Akhter, F., Jute retting: an overview. Online J. Biol. Sci. 2001, 1, 685-688.

[24] Donaghy, J. A., Levett, P. N., Haylock, R. W., Changes in microbial-populations during anaerobic flax retting. J. Appl. Bacteriol. 1990, 69, 634-641.
[25] Ge, J. P., Ling, H. Z., Zhao, D., Song, G. et al., Screening of pectinase-producing strains and preliminary study on variation of bacteria population during flax degumming. J. Nat. Sci. Heilongjiang Univ. 2007, 24, 295-300.

[26] Ling, H. Z., Ge, P., Wei, W., Ping, W. X., Analysis of bacterial community in water retting of flax. Chin. J Appl. Environ. Biol. 2009, 15, 703-707.

[27] Sun, Y. H., Sun, J. G., Zhao, J., Investigation on the bacteriologic and enzymologic parameters in the process of flax degumming. Biotechnol. Bull. 2009, 76-79.

[28] Haque, M. S., Ahmed, Z., Asaduzzaman, M., Quashem, M. A. et al., Distribution and activity of microbial population for jute retting and their impact on water of jute growing areas of Bangladesh. Pakistan J. Biol. Sci. 2002, 6, 704-706.

[29] Jiang, J., Liu, X. L., Zheng, X. Q., Xia, J.Y., Screen the microbes of flax retting. Microbiol. 1998, 25, 150-153.

[30] Tamburini, E., Leon, A. G., Perito, B., Mastromei, G., Characterization of bacterial pectinolytic strains involved in the water retting process. Environ. Microbiol. 2003, 5, 730-736.

[31] Huang, X. L., Sun, H. L., Xie, D. P., Xiang, W. et al., Screening and identification of microbial retting bacteria for flax. $J$. Biol. 2004, 21, 20-22.

[32] Peters, S., Koschinsky, S., Schwieger, F., Tebbe, C. C., Succession of microbial communities during hot composting as detected by PCR-single-strand-conformation-polymorphismbased genetic profiles of small-subunit rRNA genes. Appl. Environ. Microbiol. 2000, 66. 930- 936.

[33] Hugenholtz, P., Goebel, B. M., Pace, N. R., Impact of cultureindependent studies on the emerging phylogenetic view of bacterial diversity. J. Bacteriol. 1998, 180, 4765-4774.

[34] Hughes, J. B., Hellmann, J. J., Ricketts, T. H., Bohannan, B. J. M., Counting the uncountable: statistical approaches to estimating microbial diversity. Appl. Environ. Microbiol. 2001, 67, 4399-4406.

[35] Schwieger, F., Tebbe, C. C., A new approach to utilize PCRsingle-strand conformation polymorphism for 16S rRNA gene-based microbial community analysis. Appl. Environ. Microb. 1998, 64, 4870-4876.

[36] Dohrmann, A. B., Tebbe, C. C., Effect of elevated tropospheric ozone on the structure of bacterial communities inhabiting the rhizosphere of herbaceous plants native to Germany. Appl. Environ. Microb. 2005, 71, 7750-7758.

[37] Youssef, N. H., Elshahed, M. S., Species richness in soil bacterial communities: A proposed approach to overcome sample size bias. J. Microbiol. Methods 2008, 75, 86-91.

[38] Mandal, T. C., Saha, M. N., Retting. In: Jute retting method and mechanisation. Central Research Institute for Jute and Allied Fibres, Barrackpore, West Bengal, India 1997, pp. 13-61.

[39] Berg, G., Krechel, A., Ditz, M., Faupel, A. et al., Comparison of endophytic and ectophytic potato-associated bacterial communities and their antagonistic activity against plant pathogenic fungi. FEMS Microb. Ecol. 2005, 51, 215-229.

[40] Blackwood, C. B., Adam, O., Buyer, J. S., Phylum- and classspecific PCR primers for general microbial community analysis. Appl. Environ. Microb. 2005, 71, 6193-6198.

[41] Nechitaylo, T. J., The role of earthworm gut-associated microorganism in the fate of prions in soil, $\mathrm{PhD}$ thesis of Braunschweig University of Technology, Germany 2007.

[42] Heuer, H., Krsek, M., Baker, P., Smalla, K. et al., Analysis of actinomycete communities by specific amplification of genes encoding 16S rRNA and gel-electrophoretic separation in denaturing gradients. Appl. Environ. Microb. 1997, 63, 3233-3241. 
[43] Lieber, A., Kiesel, B., Babel, W., Microbial diversity analysis of soil by SSCP fingerprinting technique using TGGE Maxi System. in: Merbach, W., Hütsch, B. W., Augustin, J. (Eds.), Ökophysiologie des Wurzelraumes, Teubner Verlag Stuttgart, Leipzig, Wiesbaden 2003, pp. 61-65.

[44] Bassam, B. J., Anollés, G. C., Gresshoff, P. M., Fast and sensitive silver staining of DNA in polyacrylamide gels. Anal. Biochem. 1991, 196, 80-83.

[45] Dice, L. R., Measures of the amount of ecologic association between species. Ecol. 1945, 26, 297-302.

[46] Shannon, C. E., Weaver, W., A mathematical model of communication, University of Illinois Press, Urbana 1949.

[47] Maidak, B. L., Larsen, N., McCaughey, M. J., Overbeek, R. et al., The ribsomal database project. Nucleic Acid Res. 1994, 25, 109-110.

[48] Glöckner, F. O., Fuchs, B. M., Amann, R., Bacterioplankton compositions of lakes and oceans: a first comparison based on fluorescence in situ hybridization. Appl. Environ. Microb. 1999, 65, 3721-3726.

[49] Wei, H., Xu, Q., Taylor, L. E., Baker, J. O. et al., Natural paradigms of plant cell wall degradation. Curr. Opin. Biotechnol. 2009, 20, 330-338.

[50] Schloss, P. D., Handelsman, J., Biotechnological prospects from metagenomics. Curr. Opin. Biotechnol. 2003, 14, 303310.

[51] Masai, E., Katayama, Y., Ishikawa, S., Fukuda, M., Characterization of Sphingomonas paucimobilis SYK-6 genes involved in degradation of lignin-related compounds. J. Ind. Microbiol. Biot. 1999, 23, 364-373.

[52] Masai, E., Momose, K., Hara, H., Nishikawa, S. et al., Genetic and biochemical characterization of 4-carboxy-2-hydroxymuconate-6-semialdehyde dehydrogenase and its role in the protocatechuate 4,5-cleavage pathway in Sphingomonas paucimobilis SYK-6. J. Bacteriol. 2000, 182, 6651-6658.

[53] Shoham, Y., Zosim, Z., Rosenberg, E., Partial decolorization of Kraft pulp at high temperature and at high $\mathrm{pH}$ values with an extracellular xylanase from Bacillus stearothermophilus. J. Biotechnol. 1993, 30, 123-131.

[54] Kulkarni, N., Rao, M., Application of xylanase from alkaliphilic thermophilic Bacillus sp. NCIM 59 in biobleaching of bagasse pulp. J. Biotechnol. 1996, 51, 167-173.

[55] Khanongnuch, C., Asada, K., Tsuruga, H., Ooi, T. et al., [beta]-Mannanase and xylanase of Bacillus subtilis $5 \mathrm{H}$ active for bleaching of crude pulp. J. Fermentation Bioeng. 1998, 86, 461-466.

[56] Shah, A. K., Sidid, S. S., Ahmad, A., Rele, M. V., Treatment of bagasse pulp with cellulase-free xylanases from an alka- lophilic Bacillus sp. Sam-3. Bioresour. Technol. 1999, 68, 133-140

[57] Bim, M. A., Franco, T. T., Extraction in aqueous two-phase systems of alkaline xylanase produced by Bacillus pumilus and its application in kraft pulp bleaching. J. Chromatogr. $B$ Biomed. Sci. Appl. 2000, 743, 349-356.

[58] Heck, J. X., Soares, L. H., Ayub, M. A. Z., Optimization of xylanase and mannanase production by Bacillus circulans strain BL53 on solid-state cultivation. Enzyme Microb. Technol. 2005, 37, 417-423.

[59] Chauhan, S., Choudhury, B., Singh, S. N., Ghosh, P., Application of xylanase enzyme of Bacillus coagulans as a prebleaching agent on non-woody pulps. Process Biochem. 2006, 41, 226-231.

[60] Battan, B., Sharma, J., Dhiman, S. S., Kuhad, R. C., Enhanced production of cellulase-free thermostable xylanase by Bacillus pumilus ASH and its potential application in paper industry. Enzyme Microb. Technol. 2007, 41, 733-739.

[61] Zheng, L., Du. Y., Zhang, J., Biobleaching effect of xylanase preparation from an alkalophilic Bacillus sp. on ramie fibers. Biotechnol. Lett. 2000, 22, 1363-1367.

[62] Kapoor, M., Beg, Q. K., Bhushan, B., Singh, K. et al., Application of an alkaline and thermostable polygalacturonase from Bacillus sp. MG-cp-2 in degumming of ramie (Boehmeria nivea) and sunn hemp (Crotalaria juncea) bast fibres. Process Biochem. 2001, 36, 803-807.

[63] Taherzadeh, M. J., Karimi, K., Pretreatment of lignocellulosic wastes to improve ethanol and biogas production: a review. Int. J. Mol. Sci. 2008, 9, 1621-1651.

[64] Danon, M., Franke-Whittle, I. H., Insam, H., Chen, Y. et al., Molecular analysis of bacterial community succession during prolonged compost curing. FEMS. Microbiol. Ecol. 2008, 65, 133-144.

[65] Park, H. Y., Kim, K. K., Jin, L., Lee, St., Microbacterium paludicola sp. nov., a novel xylanolytic bacterium isolated from swamp forest. Int. J. Syst. Evol. Microbiol. 2006, 56, 535-539.

[66] Ryckeboer, J., Mergaert, J., Vaes, K., Klammer, S. et al., A survey of bacteria and fungi occurring during composting and self-heating processes. Ann. Microbiol. 2003, 53, 349-410.

[67] Nyanhongo, G. S., Aichernig, N., Ortner, M., Steiner, W. et al., Incorporation of 2,4,6-trinitrotoluene (TNT) transforming bacteria into explosive formulations. J. Hazard. Mater. 2009, 165, 285-290.

[68] Lalucat, J., Bennasar, A., Bosch, R., García-Valdés, E. et al., Biology of Pseudomonas stutzeri. Microbiol. Mol. Biol. Rev. 2006, 70, 510-547. 